Short report

\title{
Two techniques for the assessment of line bisection in visuo-spatial neglect: a single case study
}

\author{
PETER W HALLIGAN, JOHN C MARSHALL \\ From Rivermead Rehabilitation Centre, Oxford and the Neuropsychology Unit, University Department of \\ Clinical Neurology, The Radcliffe Infirmary, Oxford, UK
}

SUMMARY A patient with severe left neglect after surgery for basilar aneurysm is described. Her performance on freehand line bisection was compared and contrasted with the results from computerised visual display unit (VDU) presentation. In the latter format the patient makes her transections with a "mouse" controlled cursor arrow. The technique provides rigorous control over starting position and also allows self-corrections. Although left neglect persisted at longer line lengths under these conditions, the magnitude of the effect decreased significantly; the cross-over point where right displacements change to left displacements as a function of line length also varied between the three conditions (freehand, left and right computer-start).

The bisection of horizontal lines is a traditional and sensitive test for the assessment of visuo-spatial neglect. ${ }^{\prime}$ Patients with left neglect, consequent upon right posterior cerebral damage, typically place their transections considerably right of true centre. In standard clinical practice, the lines to-be-bisected are presented in free vision on the desk top and the patient makes a single, freehand response to each stimulus. Although this method is efficacious for the detection of neglect, it permits little experimental control over the variables that may be implicated in performance of the task.

We now report a computerised variant of the line bisection test that does allow greater control over task variables. We then compare the results of freehand and computerised bisection in a patient with profound left neglect.

\section{Patient}

The patient (PS), a 49 year old, right handed woman, sustained a subarachnoid haemorrhage on 25 April 1988. CT showed subarachnoid blood with mild hydrocephalus; angiography revealed an aneurysm at the bifurcation of the basilar artery. On 12 May 1988, a right fronto-temporal

Correspondence to: Peter W Halligan, Rivermead Rehabilitation Centre, Abingdon Road, Oxford OX1 4XD, UK.

Received 2 December 1988 and in revised form 29 March 1989. Accepted 6 April 1989 craniotomy was performed with clipping of the neck of the basilar aneurysm. Subsequently, PS developed left hemiplegia and dense left homonymous hemianopia with macular sparing for a full $3^{\circ}$ to the left in both eyes. There was a long standing left divergent squint, although no diplopia. The patient was also amblyopic in her left eye; acuities were 6/18 in the right eye, improving to $6 / 9$ with refraction, and 6/18 in the left eye, not improving with refraction. On admission too Rivermead Rehabilitation Centre (25 July 1988), the only? neuropsychological observation of note was florid left neglect. Assessed on 10 August 1988 with the Behavioural Inattention Test, ${ }^{2}$ PS obtained a score of $37 / 146$. This aggregate is derived from performance on: Line cancellation, letter- and star-cancellation; figure copying; line bisection and representational drawing. The cut-off score for normality is $130 / 146$.

\section{Experiment 1}

PS bisected 100 black lines, individually presented in freevision on sheets of white paper $(208 \times 298 \mathrm{~mm})$. Stimulus sheets were positioned on the desk so that the objective midpoint lay in the sagittal midplane of the patient's trunk. The horizontal lines, which varied in steps of $18 \mathrm{~mm}$ from 18 $\mathrm{mm}$ to $180 \mathrm{~mm}$ in length and were $1 \mathrm{~mm}$ in width, were centred both vertically and horizontally on the test sheet. Ten lines were displayed at each length and their order of presentation was pseudo-randomised over the entire set of 100 stimuli. PS performed each bisection with a fine pencil held in the right hand.

\section{Experiment 2}

In this condition, an Acorn BBC Master micro-computer was connected to a high resolution colour visual display unit (VDU) with dimensions 280 by $210 \mathrm{~mm}$. White lines 
(approximately $1 \mathrm{~mm}$ in width) were displayed on the dark background of the VDU. Linked to the computer, there was an AMX "mouse pointer" which controlled the (verticallyoriented) cursor arrow (15 mm long) on the screen. Two hundred lines of the same lengths employed in Experiment 1 were individually presented on the screen in pseudo-random order. Each horizontal line was centred on the screen in both vertical and horizontal dimensions. PS viewed the screen, centred on the sagittal midplane of the trunk, from a distance of approximately $450 \mathrm{~mm}$. The smallest lines $(18 \mathrm{~mm})$ accordingly subtended approximately $2.3^{\circ}$ of arc, and the largest $(180 \mathrm{~mm})$ approximately $23^{\circ}$ of arc. On each trial, the "mouse" was placed centrally on the $267 \times 216 \mathrm{~mm}$ "mousepad" that was directly in front of the screen. Each trial began when the cursor arrow (its head located $1 \mathrm{~mm}$ below the displayed line) appeared at either the left-most or the right-most end of the presented line. Simultaneous with the appearance of the cursor there was an auditory "bleep" that served to announce the beginning of a trial. PS then moved the "mouse" either left or right whilst observing the correlated left and right movement of the cursor arrow along the stimulus line. The starting position of the cursor was alternated between the left and the right end of the line. No time pressure was applied; PS stopped when satisfied that her transections were accurate. The "mouse" could be moved in either lateral direction on any trial and programming was such that the associated movement of the cursor would likewise move either leftwards or rightwards; "backtracking" and self correction was thus possible. To record the final choice of transection, the patient depressed a button located in the centre of the "mouse".

\section{Results}

The results of both experiments are shown in the table. We then display signed and absolute displacements (plus standard deviations and ranges) for all three conditions (freehand and VDU display with right and left start). Positive values $(+)$ indicate displacements right of true centre; negative values $(-)$ are left of centre.

Regression analyses (line length against transection displacement) indicate a linear relationship between stimulus magnitude and bisection error; productmoment correlations (line length and standard deviation of the transection displacements) show that variability in bisection error increases as a function of stimulus magnitude.

The best-fitting regression equation for freehand performance (signed displacements) is $-10.53+$ $(0.32 \times$ line length), with $98 \%$ of the variance thereby accounted for. The linear correlation between line length and standard deviation is $r=+0.63(p<0.05)$. The equivalent equations for VDU display are -19.9 $+(0.3469 \times$ line length $)$ for right start and $-11 \cdot 10+$ $(0.06475 \times$ line length) for left start. These equations account for $90 \%$ and $58 \%$ of the respective variances. With right start, the correlation between line length and standard deviation is $r=+0.46$ (NS); with left
Table Displacements from midpoint on line bisection

\begin{tabular}{|c|c|c|c|c|}
\hline $\begin{array}{l}\text { Line } \\
\text { length }\end{array}$ & Condition & $\begin{array}{l}\text { Signed } \\
\text { displacement } \\
(S D)\end{array}$ & $\begin{array}{l}\text { Absolute } \\
\text { displacement } \\
\text { (SD) }\end{array}$ & Range \\
\hline $180 \mathrm{~mm}$ & $\begin{array}{l}\text { Freehand } \\
\text { Right start } \\
\text { Left start }\end{array}$ & $\begin{array}{l}+47 \cdot 1(4.65) \\
+44 \cdot 3(16 \cdot 3) \\
+4 \cdot 8(18 \cdot 0)\end{array}$ & $\begin{array}{l}47 \cdot 1(4 \cdot 65) \\
44 \cdot 3(16 \cdot 3) \\
12 \cdot 4(13 \cdot 9)\end{array}$ & $\begin{array}{l}+38 /+53 \\
+25 /+68 \\
-23 /+45\end{array}$ \\
\hline $162 \mathrm{~mm}$ & $\begin{array}{l}\text { Freehand } \\
\text { Right start } \\
\text { Left start }\end{array}$ & $\begin{array}{l}+38.5(10.48) \\
+43.6(12.1) \\
-0.9(12.8)\end{array}$ & $\begin{array}{c}38.5(10.48) \\
43.6(12.1) \\
9.5(8.0)\end{array}$ & $\begin{array}{l}+20 /+52 \\
+22 /+59 \\
-29 /+13\end{array}$ \\
\hline $144 \mathrm{~mm}$ & $\begin{array}{l}\text { Freehand } \\
\text { Right start } \\
\text { Left start }\end{array}$ & $\begin{array}{l}+36.4(8 \cdot 19) \\
+29.3(11.2) \\
-1.6(13.4)\end{array}$ & $\begin{array}{l}36 \cdot 4(8 \cdot 19) \\
29 \cdot 3(11 \cdot 2) \\
10 \cdot 3(8 \cdot 1)\end{array}$ & $\begin{array}{l}+19 /+47 \\
+18 /+56 \\
-13 /+31\end{array}$ \\
\hline $126 \mathrm{~mm}$ & $\begin{array}{l}\text { Freehand } \\
\text { Right start } \\
\text { Left start }\end{array}$ & $\begin{array}{l}+34.5(2.99) \\
+21.2(9.7) \\
-7.6(7.5)\end{array}$ & $\begin{array}{c}34.5(2.99) \\
21.2(9 \cdot 7) \\
7.9(7 \cdot 1)\end{array}$ & $\begin{array}{l}+30 /+39 \\
+5 /+34 \\
-22 /+2\end{array}$ \\
\hline $108 \mathrm{~mm}$ & $\begin{array}{l}\text { Freehand } \\
\text { Right start } \\
\text { Left start }\end{array}$ & $\begin{array}{l}+26.8(5.60) \\
+20.5(12.1) \\
-8.6(5.9)\end{array}$ & $\begin{array}{c}26 \cdot 8(5 \cdot 60) \\
20 \cdot 5(12 \cdot 1) \\
9 \cdot 4(4 \cdot 6)\end{array}$ & $\begin{array}{l}+19 /+36 \\
+4 /+41 \\
-14 /+4\end{array}$ \\
\hline $90 \mathrm{~mm}$ & $\begin{array}{l}\text { Freehand } \\
\text { Right start } \\
\text { Left start }\end{array}$ & $\begin{array}{l}+22.2(4.30) \\
-0.7(16.0) \\
-1.9(7.3)\end{array}$ & $\begin{array}{c}22 \cdot 2(4 \cdot 30) \\
12 \cdot 2(9 \cdot 6) \\
5 \cdot 9(4 \cdot 3)\end{array}$ & $\begin{array}{l}+15 /+29 \\
-18 /+23 \\
-11 /+14\end{array}$ \\
\hline $72 \mathrm{~mm}$ & $\begin{array}{l}\text { Freehand } \\
\text { Right start } \\
\text { Left start }\end{array}$ & $\begin{array}{l}+11.8(3.99) \\
-2.2(19.0) \\
-5.4(5.4)\end{array}$ & $\begin{array}{c}11.8(3.99) \\
15.8(9 \cdot 6) \\
6.5(4 \cdot 2)\end{array}$ & $\begin{array}{l}+4 /+17 \\
-32 /+29 \\
-14 /+4\end{array}$ \\
\hline $54 \mathrm{~mm}$ & $\begin{array}{l}\text { Freehand } \\
\text { Right start } \\
\text { Left start }\end{array}$ & $\begin{array}{l}+5.0(5.0) \\
-1.4(11.3) \\
-8.8(4.2)\end{array}$ & $\begin{array}{l}6 \cdot 0(3 \cdot 6) \\
9 \cdot 4(5 \cdot 7) \\
8 \cdot 8(4 \cdot 2)\end{array}$ & $\begin{array}{l}-3 /+12 \\
-20 /+16 \\
-16 /-4\end{array}$ \\
\hline $36 \mathrm{~mm}$ & $\begin{array}{l}\text { Freehand } \\
\text { Right start } \\
\text { Left start }\end{array}$ & $\begin{array}{l}-0.7(2.70) \\
-5.2(8.2) \\
-9.7(5.8)\end{array}$ & $\begin{array}{r}2.3(1.6) \\
7.4(6.0) \\
10.1(5.0)\end{array}$ & $\begin{array}{l}-5 /+3 \\
-20 /+5 \\
-18 /+2\end{array}$ \\
\hline $18 \mathrm{~mm}$ & $\begin{array}{l}\text { Freehand } \\
\text { Right start } \\
\text { Left start }\end{array}$ & $\begin{array}{l}-4 \cdot 4(2.63) \\
-5 \cdot 0(3.0) \\
-7 \cdot 2(4 \cdot 4)\end{array}$ & $\begin{array}{l}4.6(2.2) \\
5 \cdot 0(3.0) \\
7 \cdot 2(4 \cdot 4)\end{array}$ & $\begin{array}{l}-8 /+1 \\
-9 /+2 \\
-14 /-4\end{array}$ \\
\hline
\end{tabular}

start the value is $r=+0.87(p<0.01)$. The data are displayed graphically in the figure.

It can be seen that starting with the cursor arrow on the left has dramatically decreased the magnitude of left neglect; at all ten line lengths, the transection point with left start is placed further from the rightmost end

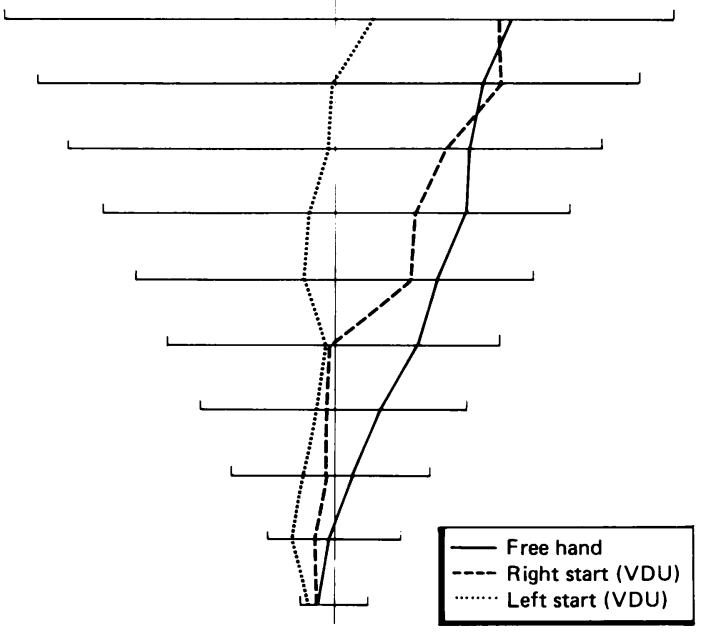

Fig Mean displacements as a function of line length in the three conditions (freehand, right start and left start). 
of the stimulus line than is the case with right start $(p=$ 0.001 , binomial test). The cross-over effect, previously documented in Halligan and Marshall ${ }^{3}$ is confirmed; rightward displacements at longer line lengths cross over the midpoint and become leftward displacements for shorter lines. With left start, 9/10 mean displacements are to the left of centre $(p=0.011$, binomial test), and only performance on the longest line $(180 \mathrm{~mm})$ now indicates left neglect.

Freehand performance is similar to that found with right start on VDU presentation; the multipliers in the two regression equations $(0.32$ and 0.3469 , respectively) are very comparable. Nonetheless, for mean displacements at nine out of the 10 line lengths, freehand transections are closer to the rightmost point of the presented lines than are right start VDU transections $(p=0.011$, binomial test).

\section{Discussion}

These results help resolve a controversy about the efficacy of cueing in neglect. ${ }^{45}$ Heilman and Valenstein $^{4}$ failed to reduce left neglect on freehand line bisection by cueing patients to attend to the neglected field; in their experiment, a letter was placed at each end of the to-be-dissected line and patients reported either the right-end or the left-end letter before placing their bisection marks. Heilman and Valenstein report that "Performance in trials when subjects were required to look to the left before bisecting a line did not differ from when they were required to look right." In contrast, Riddoch and Humphreys ${ }^{5}$ did find that left neglect was reduced by left-end letter reporting, both in conditions where there was only a solitary cue present and with forced-choice left report when there was a competing letter in the right field.

One problem with such cueing studies is that the cue-task (letter-report) is not intrinsically linked to the experimental task (line bisection). It is thus possible that some patients may perform the cue-task correctly but then switch to what is (from an informationprocessing standpoint) a totally different task (bisecting a line) without any "attentional" carry-over from the position of the cue. In our method of VDU presentation, the spatial cue is much more firmly locked to the actual line-bisection task. Under these circumstances, starting with the cursor on the left effects a major reduction in right displacement.

That freehand performance is more similar to the right start than the left start VDU condition implies that, in the absence of strong cues in left space, the patient's attention is captured and held by right hemispace stimulation. ${ }^{6}$ The efficacy of cueing with a movable cursor in left space suggests that the technique might be successfully employed in the remediation of neglect; perceptual feedback from the cursor clearly allows for the possibility of useful selfcorrection by the patient.

The five patients studied by Riddoch and Humphreys ${ }^{5}$ all had left homonymous hemianopia. In contrast, of the six patients reported by Heilman and Valenstein, ${ }^{4}$ only two were hemianopic. It is thus possible that cueing is maximally effective in patients, who, like PS, have visual field deficits. In future studies, we intend to investigate neglect patients without hemianopia, using the same computerised methodology employed here. At this time, the interaction (if any) between visual field deficit and neglect as measured on traditional clinical tests remains obscure. In studies that use either letter-cues or a movable cursor, the direction of eye-movements will be rightwards (that is, towards the good field) with left cueing and leftwards (that is, towards the bad field) with right cueing. The possibility thus arises that cueing in patients with and without hemianopia may have different behavioural consequences. Likewise, the extent of macular sparing may be related to the quantitative relationship between transection diso placements and line length. For PS, the lines that she consistently transects to the left of true centre (length 8 of 36 and $18 \mathrm{~mm}$ ) fall well within the visual angle subtended by her intact macular vision.

This study was supported by the Chest, Heart and Stroke Association (PWH) and by the Medicap Research Council (JCM).

\section{References}

1 Schenkenberg T, Bradford DC, Ajax ET. Line bisection and unilateral visual neglect in patients with neurological impairment. Neurology 1980;30:509-17.

2 Wilson B, Cockburn J, Halligan PW. Behavioural Inattention Test. Titchfield, Hants: Thames Valley Test Company, 1987.

3 Halligan PW, Marshall JC. How long is a piece of string? A study of line bisection in a case of visual neglect. Cortex 1988;24:321-8.

4 Heilman KM, Valenstein E. Mechanisms underlying hemispatial neglect. Ann Neurol 1979;5:166-70.

5 Riddoch MJ, Humphreys GW. The effect of cueing on unilateral neglect. Neuropsychologia 1983;21:589-99.

6 Posner MI, Walker JA, Friedrich FA, Rafal RD. How do the parietal lobes direct covert attention? Neuropsychologia 1987;25:135-45.

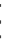

